Research Paper

\title{
Expression and Significances of G-Protein-Coupled Receptor Kinase 3 in Hepatocellular Carcinoma
}

\author{
Ye Jin ${ }^{1}$, Zhi-Yong Liang², Wei-Xun Zhou ${ }^{2}$, Li Zhou ${ }^{3 凶}$ \\ 1. Clinical Research Laboratory, Peking Union Medical College Hospital, Chinese Academy of Medical Sciences/Peking Union Medical College, Beijing \\ 100730, China \\ 2. Department of Pathology, Peking Union Medical College Hospital, Chinese Academy of Medical Sciences/Peking Union Medical College, Beijing 100730, \\ China \\ 3. Department of General Surgery, Peking Union Medical College Hospital, Chinese Academy of Medical Sciences/Peking Union Medical College, Beijing \\ 100730, China \\ $\triangle$ Corresponding author: Dr. Li Zhou, Department of General Surgery, Peking Union Medical College Hospital, Chinese Academy of Medical Sciences/Peking \\ Union Medical College, Beijing 100730, China. Tel: 86-10-69156007; Fax: 86-10-69156010; E-mail: lizhou02@hotmail.com \\ (c) Ivyspring International Publisher. This is an open access article distributed under the terms of the Creative Commons Attribution (CC BY-NC) license \\ (https://creativecommons.org/licenses/by-nc/4.0/). See http://ivyspring.com/terms for full terms and conditions.
}

Received: 2017.01.15; Accepted: 2017.04.30; Published: 2017.07.05

\begin{abstract}
Objective: To investigate expression, clinical, pathologic and prognostic significances of G-protein-coupled receptor kinase 3 (GRK3) in hepatocellular carcinoma (HCC).

Materials and Methods: Expression of GRK3 was detected using Western blotting and tissue microarray-based immunohistochemical staining in 8 and 395 patients (training set: $n=164$; validation set: $n=231$ ) with HCC underwent hepatectomy, respectively. GRK3 expression and its associations with cliniopathologic variables and tumor-specific survival were evaluated.

Results: Expression of GRK3 was lower in tumor than in non-tumor tissues from 4 out of 8 patients. In the training set, the $\mathrm{H}$-score of tumoral GRK3 staining was much lower than that in adjacent non-tumor liver tissues. In addition, GRK3 was associated with tumor-node-metastasis (TNM) stage and serum $\alpha$-fetoprotein (AFP) level. Patients with high GRK3 tumors were found to carry significantly better tumor-specific survival, compared with those with low GRK3 ones. Furthermore, GRK3 was identified as one of independent predictors of favorable prognosis, adjusted for clinicopathologic parameters. Importantly, these results were further validated in the independent validation set. In all patients and 7 out of 10 subgroups, GRK 3 was also revealed to be prognostic.

Conclusions: GRK3 is down-regulated and predicts good prognosis in HCC. Therefore, GRK3 might function as a tumor suppressor gene in HCC.
\end{abstract}

Key words: hepatocellular carcinoma, G-protein-coupled receptor kinase 3, survival

\section{Introduction}

It is well known that hepatocellular carcinoma (HCC) is highly prevalent worldwide, especially in Band C-type hepatitis virus endemic areas [1]. In addition, the overall prognosis of HCC remains poor, although some improved results have been achieved by curative interventions, such as hepatic resection and liver transplantation in highly selected patients [2,3]. Therefore, factors affecting prognosis of HCC were long of interest. Except for conventional clinical and pathologic variables that were previously reported and summarized, such as portal vein thrombosis, tumor size, alpha-fetoprotein (AFP), Child-Pugh class and tumor-node-metastasis (TNM) stage [4-6], prognostic values of molecules that are involved in initiation and progression of HCC, including genes/proteins, microRNAs (miRNAs) and long non-coding RNAs (lncRNAs) have been gradually found [7-9]. However, novel promising candidates need to be further explored.

G protein-coupled receptor kinase 3 (GRK3) is 
one of seven isoforms of GRKs that phosphorylate and desensitize agonist-bound G protein-coupled receptors (GPCRs) [10,11]. It was previously demonstrated that GRK3 plays important roles in the nerve system [12-14]. Interestingly, data concerning GRK3 seem to be controversial in different kinds of human malignant tumors [15-18]. In glioblastoma, GRK3 was found to be frequently decreased and to reduce the trophic effect of endothelial cells on tumor cells [15]. Recent results from breast cancer also suggested its negative impact on migration, invasion, and metastasis [16]. However, Li et al. reported that GRK3 not only maintained survival and proliferation of metastatic cells, but also promoted growth, neuroendocrine differentiation and metastasis in prostate cancer $[17,18]$. Therefore, the biological effects of GRK3 might be tissue-type specific. This phenomenon might influence the impact of the molecule on clinical features and long-term outcomes in patients with different malignancies. Thus far, expression, clinicopathologic and prognostic significances of GRK3 in cancer remain unknown.

The present study was designed to address these issues, based on Chinese patients with HCC.

\section{Materials and Methods}

\section{Patients and Samples}

Totally, 8 and 395 patients with HCC who underwent hepatectomy were enrolled, respectively. Paired tumor and adjacent non-tumor liver tissues were obtained. Of 8 patients whose samples were collected for Western blotting, 6 were male and 2 were female. Ages ranged from 16 to 60 years (median: 53 years). On the other hand, 395 individuals whose samples for immunohistochemistry were divided into two independent sets, i.e. training $(2010-2012, n=164)$ and validation (2005-2009, $\mathrm{n}=231$ ) ones. Among the patients, $334(84.6 \%)$ were male and $61(15.4 \%)$ were female, with the median age of 52 years (range: 17-79 years). The tested clinicopathologic parameters were age, sex, hepatitis B surface antigen (HBsAg), cirrhosis, tumor size, vascular invasion, Edmondson -Steiner grade [19], TNM stage and AFP level. Tumor size was first measured in preoperative imaging and proven during operation. Vascular invasion (VI) and Edmondson-Steiner grade were determined by post-surgical histological examinations. Patient clinicopathologic features are shown in Table 1. The project was approved by the Institutional Ethics Committee and the informed consent of patients was obtained.
Table 1. Associations between GRK3 expression and clinicopathologic features in HCC

\begin{tabular}{|c|c|c|c|c|c|c|c|c|}
\hline \multirow[t]{2}{*}{ Variables } & \multirow[b]{2}{*}{$\mathrm{n}$} & \multicolumn{3}{|c|}{ GRK3 in training set } & \multicolumn{4}{|c|}{ GRK3 in validation set } \\
\hline & & high & low & $P^{*}$ & $\mathrm{n}$ & high & low & $P^{*}$ \\
\hline Age & & & & 0.115 & & & & 0.204 \\
\hline$\geq 52$ years & 88 & 42 & 46 & & 116 & 15 & 101 & \\
\hline$<52$ years & 76 & 27 & 49 & & 115 & 9 & 106 & \\
\hline Sex & & & & 0.170 & & & & 0.089 \\
\hline Male & 137 & 124 & 13 & & 197 & 42 & 155 & \\
\hline Female & 27 & 22 & 5 & & 34 & 3 & 31 & \\
\hline HBsAg & & & & 0.542 & & & & 0.089 \\
\hline Positive & 141 & 101 & 40 & & 174 & 40 & 134 & \\
\hline Negative & 20 & 13 & 7 & & 44 & 5 & 39 & \\
\hline Cirrhosis & & & & 0.243 & & & & 0.155 \\
\hline Present & 145 & 105 & 40 & & 191 & 3 & 188 & \\
\hline Absent & 17 & 10 & 7 & & 38 & 2 & 36 & \\
\hline Tumor size & & & & 0.018 & & & & 0.090 \\
\hline$\geq 5 \mathrm{~cm}$ & 97 & 47 & 50 & & 138 & 95 & 43 & \\
\hline$<5 \mathrm{~cm}$ & 67 & 45 & 22 & & 74 & 59 & 15 & \\
\hline VI & & & & 0.022 & & & & 0.118 \\
\hline Present & 76 & 15 & 61 & & 116 & 37 & 79 & \\
\hline Absent & 80 & 29 & 51 & & 92 & 39 & 53 & \\
\hline E-S grade & & & & 0.968 & & & & $<0.001$ \\
\hline I-II & 89 & 46 & 43 & & 158 & 117 & 41 & \\
\hline III-IV & 75 & 39 & 36 & & 73 & 37 & 36 & \\
\hline TNM stage & & & & 0.023 & & & & $<0.001$ \\
\hline I-II & 86 & 60 & 26 & & 132 & 113 & 19 & \\
\hline III-IV $_{\text {A }}$ & 71 & 37 & 34 & & 91 & 59 & 32 & \\
\hline AFP level & & & & $<0.001$ & & & & 0.035 \\
\hline$>20 \mathrm{ng} / \mathrm{ml}$ & 102 & 9 & 93 & & 136 & 24 & 112 & \\
\hline$\leq 20 \mathrm{ng} / \mathrm{ml}$ & 53 & 17 & 36 & & 80 & 24 & 56 & \\
\hline
\end{tabular}

*Partial data were not available, and statistical analyses were performed using available data. GRK3, G-protein-coupled receptor kinase 3; HCC, hepatocellular carcinoma; HBsAg, hepatitis B surface antigen; VI, Vascular invasion; E-S,

Edmondson-Steiner; TNM, tumor-node-metastasis; AFP, $\alpha$-fetoprotein.

\section{Western Blotting}

Proteins were extracted according to tissue protein extraction protocols. Protein extracts $(60 \mu \mathrm{g} /$ lane) were separated by sodium dodecyl sulfate polyacrylamide gel electrophoresis (SDS-PAGE) followed by transfer to polyvinylidene difluoride (PVDF) membranes and blocking with $5 \%$ bovine serum albumin (BSA) for $2 \mathrm{~h}$. A rabbit anti-human monoclonal antibody against GRK3 (Abcam, Cambridge, UK) were incubated overnight at $4^{\circ} \mathrm{C}$. Then, a horseradish peroxidase-conjugated secondary antibody was incubated for $2 \mathrm{~h}$ at room temperature. Blots were washed three times and exposed to chemiluminescence reagents (Merck Millipore, Darmstadt, Germany). GAPDH was used as the internal control.

\section{Tissue Microarray (TMA) Construction}

TMAs were constructed based on formalin-fixed paraffin-embedded blocks of HCC. Firstly, representtative areas within tumor and adjacent non-tumor liver tissues were re-identified. Then, cores with a diameter of $1.5 \mathrm{~mm}$ were sampled. Finally, TMAs were constructed using a manual tissue arrayer (Beecher Instruments, Sun Prairie, WI). 


\section{Immunohistochemical Staining}

The same primary antibody for GRK3 was used for staining. In the first, $4 \mu \mathrm{m}$-thick sections were mounted, deparaffinized in xylene and rehydrated in graded ethanol. Antigen retrieval was carried out in an autoclave for $5 \mathrm{~min}$. Subsequently, slides were incubated with hydrogen peroxide (3\%) for $10 \mathrm{~min}$ to block endogenous peroxidase. Slides were then incubated overnight with the primary antibody (1: $100)$ at $4^{\circ} \mathrm{C}$. Non-immune serum at the same dilution was applied as the negative control. After washing in phosphate buffered saline (PBS), the horseradish peroxidase (HRP)-labeled secondary antibody was added for an incubation of $30 \mathrm{~min}$. Diaminobenzidine was adopted as a chromogen. Finally, slides were counterstained using hematoxylin.

\section{Staining Evaluation}

Two senior pathologists who had no prior information of clinicopathologic and follow-up data (Z.Y. L. and W.X. Z.) independently evaluated the slides, and discussed for the consensus when they were divergent. The positive signal was defined as brown coloration in tumor and non-tumor liver cells. The H-score [20], considering both positive cell proportion and staining intensity and being widely adopted in immunostaining studies [21,22], was used as the staining evaluation criteria. The $\mathrm{H}$-score values with the largest youden index (YI) for survival and clinicopathologic variables within corresponding receiver operating characteristic (ROC) curves were selected as cut-off ones, as previously reported [23].
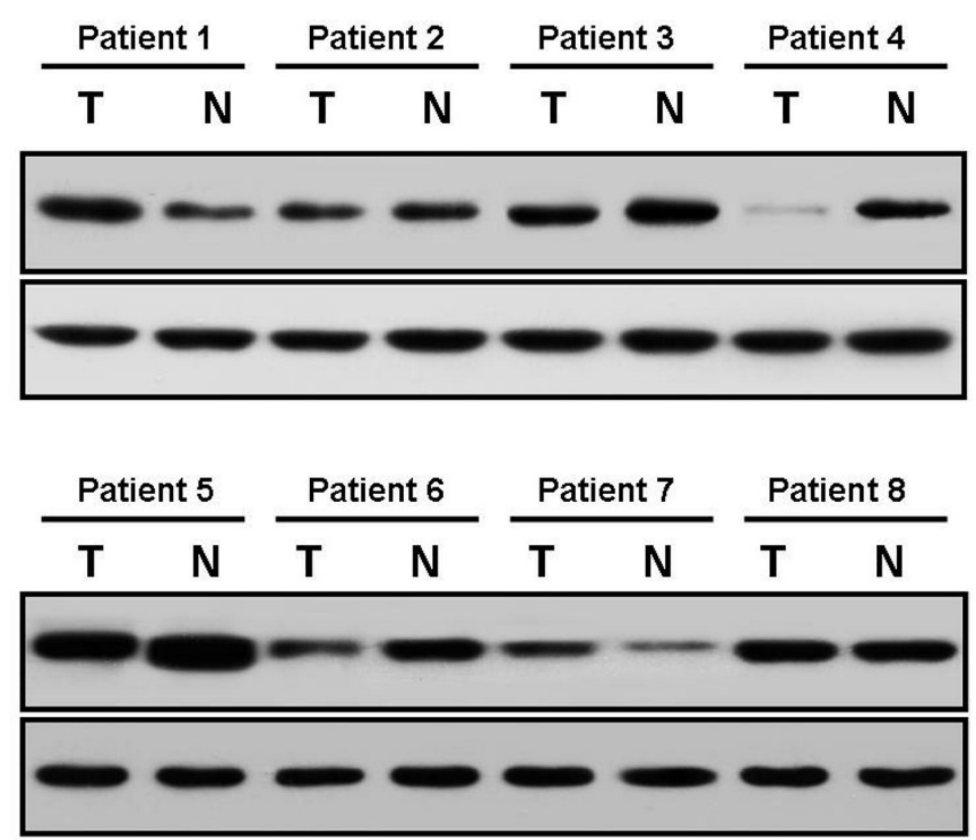
GAPDH
GRK3

GAPDH

GRK3

\section{Follow-Up}

All patients underwent follow-up. For the training set, median follow-up time was 20.0 months (range, 1.4 to 44.0 months). For the validation set, the follow-up time ranged from 1.3 to 115.8 months (median, 28.9 months).

\section{Statistical Analyses}

H-scores of GRK3 staining in tumor and adjacent non-tumor liver tissues were compared by Mann-Whitney $U$ test. The associations between GRK3 expression and clinicopathologic variables were determined using Chi-square analysis. Patient tumor-specific survival was analyzed by KaplanMeier method and log-rank test. Multivariate prognostic factor analyses were performed using Cox regression (Proportional hazard model). The statistical software package, SPSS11.5 (SPSS Inc, Chicago, IL), was applied for all the analyses. A $P$ value less than 0.05 was defined as statistically significant.

\section{Results}

\section{Expression of GRK3 in Patients of HCC (Detected by Western Blotting)}

Western blotting showed that GRK3 was degressively expressed in 4 out of 8 tumor tissues (patients 3, 4, 5 and 6), in contrast to corresponding non-tumor ones (Fig. 1). Besides, its expression in tumors was higher than and equal to that in normal tissues in 2 ( 1 and 7) and 2 ( 2 and 8 ) patients, respecttively. The corresponding hematoxylin and eosin (H\&E) staining images of tumor and non-tumor tissues of these patients were shown to provide histological evidence in Fig. S1.

\section{Cut-off Values of GRK3 for Survival and Clinicopathologic Variables of HCC}

According to ROC curves for main clinicopathologic variables of the training set (Fig. S2), cut-off values of GRK3 $\mathrm{H}$-score for survival, AFP level, Edmondson-Steiner grade, vascular invasion, tumor size and TNM stage were 51.25, 160, $68.75,109.375,61.875$ and 51.25, respectively. 

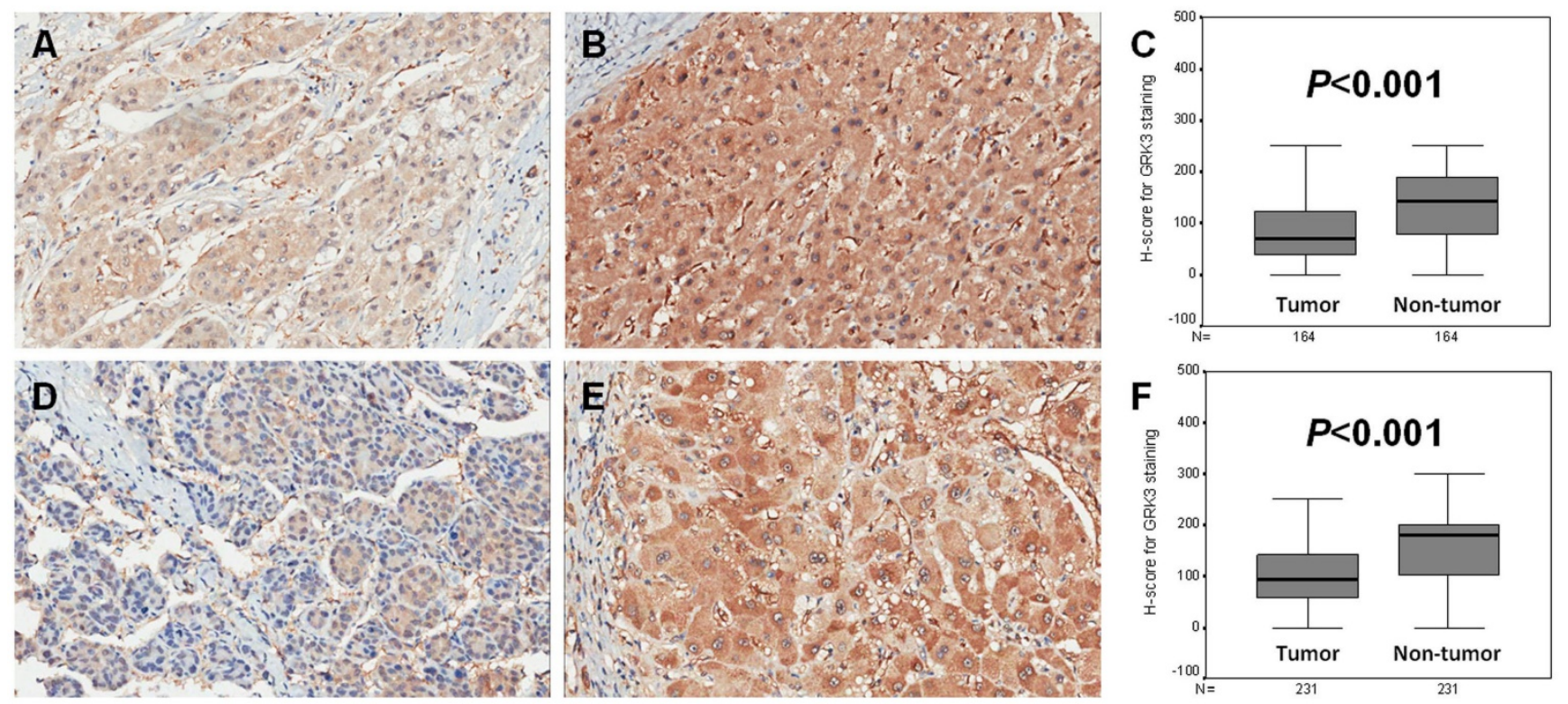

Figure 2. Expression of $G$ protein-coupled receptor kinase 3 (GRK3) in two sets of hepatocellular carcinoma (HCC). (A) GRK3 expression in tumor tissues of training set (×200); (B) GRK3 expression in adjacent non-tumor liver tissues of training set $(\times 200)$; (C) The H-score in tumor tissues was statistically lower than that in adjacent non-tumor liver ones of training set; (D) GRK3 expression in tumor tissues of validation set $(\times 200)$; (E) GRK3 expression in adjacent non-tumor liver tissues of validation set $(\times 200)$; (F) The $\mathrm{H}$-score in tumor tissues was statistically lower than that in adjacent non-tumor liver ones of validation set.
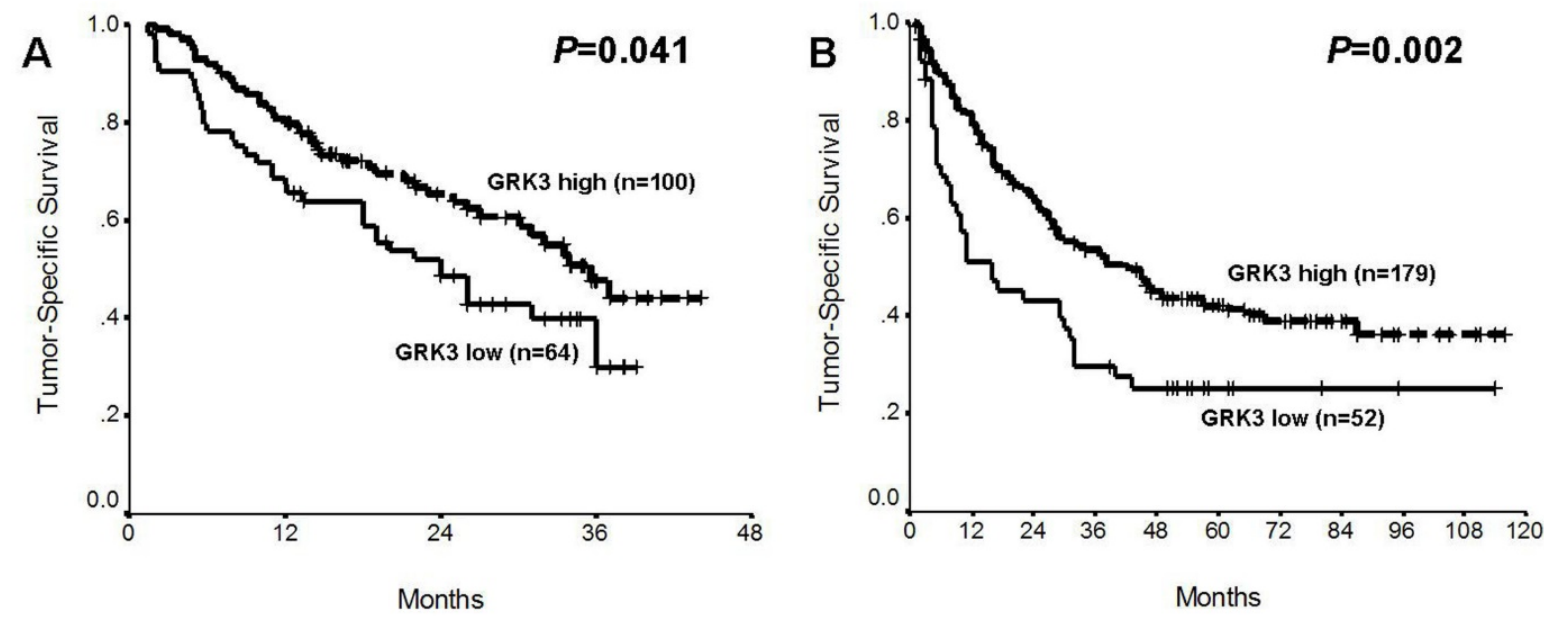

Figure 3. Prognostic impacts of $G$ protein-coupled receptor kinase 3 (GRK3) in two sets of hepatocellular carcinoma (HCC). (A) Training set; (B) Validation set.

\section{GRK3 Expression and Associations with Clinicopathologic Features in HCC}

It was revealed that the positive signal of GRK3 was basically located in the cytoplasm of both tumor and adjacent non-tumor liver tissues (Fig. 2A, B, D and $\mathrm{E}$ ). The $\mathrm{H}$-scores of GRK3 in tumors were much lower than those in adjacent non-tumor liver tissues in both training and validation sets (All $P<0.001$; Fig. 2C and F).

As shown in Table 1, GRK3 expression was negatively associated with tumor size $(P=0.018)$, VI $(P=0.022)$, TNM stage $(P=0.023)$ and serum AFP level $(P<0.001)$ in the training set. On the other hand, this protein was related to Edmondson-Steiner grade $(P<0.001)$, TNM stage $(P<0.001)$ and serum AFP level
$(P=0.035)$ in the validation set (Table 1$)$. Other statistically significant correlations were not found.

\section{Prognostic Significance of GRK3 in HCC}

Univariate analysis showed that patients with high GRK3 expressed HCCs carried more favorable tumor-specific survival, in comparison to those with low GRK3 tumors, in both training and validation sets of HCC ( $P=0.041$ and 0.002 , respectively; Fig. 3, Table 2 and 3). Using multivariate Cox regression test, GRK3 expression was identified as an independent predictor of good prognosis in training and validation sets of HCC $(P=0.006$ and 0.012 , respectively; Table 2 and 3 ), adjusted for tested conventional clinicopathologic parameters, including age, sex, HBsAg, cirrhosis, tumor size, vascular invasion, EdmondsonSteiner grade, TNM stage and AFP level. 
Table 2. Prognostic analysis for tumor-specific survival in training set of $\mathrm{HCC}$

\begin{tabular}{|c|c|c|c|c|c|c|c|}
\hline \multirow[t]{2}{*}{ Variables } & \multicolumn{3}{|c|}{ Univariate } & \multirow[b]{2}{*}{$P^{*}$} & \multicolumn{3}{|c|}{ Multivariate } \\
\hline & $\mathrm{n}$ & $\begin{array}{l}\text { median } \pm \\
\text { SE }\end{array}$ & $95 \% \mathrm{CI}$ & & $\overline{\mathrm{HR}}$ & $95 \% \mathrm{CI}$ & $P^{*}$ \\
\hline Age & & & & 0.007 & & & 0.204 \\
\hline$\geq 52$ years & 88 & $31.4 \pm 1.7$ & $27.7-34.4$ & & 0.691 & $0.390-1.223$ & \\
\hline$<52$ years & 76 & $24.0 \pm 1.8$ & $20.5-27.6$ & & 1 & & \\
\hline Sex & & & & 0.860 & & & 0.574 \\
\hline Male & 137 & $31.0 \pm 3.4$ & $24.4-37.6$ & & 0.779 & $0.327-1.858$ & \\
\hline Female & 27 & $33.9 \pm 11.0$ & $12.4-55.5$ & & 1 & & \\
\hline HBsAg & & & & 0.078 & & & 0.958 \\
\hline Positive & 141 & $27.1 \pm 1.4$ & $24.3-29.8$ & & 1.037 & $0.272-3.949$ & \\
\hline Negative & 20 & $34.6 \pm 3.2$ & $28.4-40.9$ & & 1 & & \\
\hline Cirrhosis & & & & 0.177 & & & 0.388 \\
\hline Present & 145 & $27.4 \pm 1.4$ & $24.6-30.1$ & & 2.011 & $0.412-9.831$ & \\
\hline Absent & 17 & $32.8 \pm 3.4$ & $26.1-39.5$ & & 1 & & \\
\hline Tumor size & & & & $<0.001$ & & & 0.262 \\
\hline$\geq 5 \mathrm{~cm}$ & 97 & $24.1 \pm 1.6$ & $20.9-27.3$ & & 1.412 & $0.773-2.581$ & \\
\hline$<5 \mathrm{~cm}$ & 67 & $33.2 \pm 1.8$ & $20.8-36.7$ & & 1 & & \\
\hline VI & & & & 0.011 & & & 0.764 \\
\hline Present & 76 & $24.3 \pm 1.9$ & $20.5-28.0$ & & 1.089 & $0.624-1.903$ & \\
\hline Absent & 80 & $31.2 \pm 1.7$ & $27.8-34.6$ & & 1 & & \\
\hline E-S grade & & & & 0.002 & & & 0.015 \\
\hline I-II & 89 & $31.5 \pm 1.6$ & $28.4-34.6$ & & 1 & & \\
\hline III-IV & 75 & $23.0 \pm 1.9$ & $19.3-26.8$ & & 2.046 & $1.149-3.642$ & \\
\hline TNM stage & & & & $<0.001$ & & & 0.038 \\
\hline I-II & 86 & $34.5 \pm 1.5$ & $31.5-37.4$ & & 1 & & \\
\hline III-IV $_{A}$ & 71 & $21.5 \pm 1.9$ & $17.8-25.3$ & & 1.961 & $1.036-3.712$ & \\
\hline AFP level & & & & 0.096 & & & 0.333 \\
\hline$>20 \mathrm{ng} / \mathrm{ml}$ & 102 & $26.0 \pm 4.7$ & $16.7-35.3$ & & 1.331 & $0.746-2.375$ & \\
\hline$\leq 20 \mathrm{ng} / \mathrm{ml}$ & 53 & $33.5 \pm 5.1$ & $23.6-43.4$ & & 1 & & \\
\hline \multicolumn{2}{|c|}{ GRK3 expression } & & & 0.041 & & & 0.006 \\
\hline High & 100 & $35.5 \pm 3.0$ & $29.6-41.4$ & & 0.482 & $0.285-0.814$ & \\
\hline Low & 64 & $24.0 \pm 3.5$ & $17.1-30.9$ & & 1 & & \\
\hline $\begin{array}{l}\text { *Partial dat } \\
\text { available da } \\
\text { interval; HI } \\
\text { invasion; E- }\end{array}$ & we & $\begin{array}{l}\text { ot avail } \\
\text {, hepat } \\
\text { ratio; }\end{array}$ & $\begin{array}{l}\text { and sta } \\
\text { lular car } \\
\mathrm{Ag} \text {, hepa }\end{array}$ & tical a & $\begin{array}{l}\text { we } \\
\text { dar } \\
\text { ntig }\end{array}$ & $\begin{array}{l}\text { erformed } \\
\text { ror; CI, cor } \\
\text { VI, Vascul } \\
\text { is; AFP, }\end{array}$ & ing \\
\hline
\end{tabular}

Table 3. Prognostic analysis for tumor-specific survival in validation set of $\mathrm{HCC}$

\begin{tabular}{|c|c|c|c|c|c|c|c|}
\hline \multirow[t]{2}{*}{ Variables } & \multicolumn{3}{|c|}{ Univariate } & \multirow[b]{2}{*}{$P^{*}$} & \multicolumn{3}{|c|}{ Multivariate } \\
\hline & $\mathrm{n}$ & median \pm SE & $95 \% \mathrm{CI}$ & & $\overline{\mathrm{HR}}$ & $95 \% \mathrm{CI}$ & $P^{*}$ \\
\hline Age & & & & 0.691 & & & 0.353 \\
\hline$\geq 52$ years & 116 & $31.0 \pm 4.4$ & $22.3-39.7$ & & 1.202 & $0.815-1.774$ & \\
\hline$<52$ years & 115 & $33.0 \pm 8.0$ & $17.2-48.8$ & & 1 & & \\
\hline Sex & & & & 0.679 & & & 0.850 \\
\hline Male & 197 & $32.0 \pm 5.0$ & $22.2-41.8$ & & 1.058 & $0.590-1.896$ & \\
\hline Female & 34 & $29.0 \pm 8.7$ & $11.9-46.1$ & & 1 & & \\
\hline HBsAg & & & & 0.351 & & & 0.334 \\
\hline Positive & 174 & $30.0 \pm 4.1$ & $22.0-38.0$ & & 1.351 & $0.734-2.485$ & \\
\hline Negative & 44 & $69.0 \pm 24.0$ & 21.9-116.1 & & 1 & & \\
\hline Cirrhosis & & & & 0.193 & & & 0.958 \\
\hline Present & 191 & $29.0 \pm 4.1$ & $21.0-37.0$ & & 0.982 & $0.502-1.923$ & \\
\hline Absent & 38 & $49.0 \pm 18.2$ & $13.2-84.8$ & & 1 & & \\
\hline Tumor size & & & & 0.021 & & & 0.526 \\
\hline$\geq 5 \mathrm{~cm}$ & 138 & $28.0 \pm 3.8$ & $20.5-35.5$ & & 1.154 & $0.741-1.797$ & \\
\hline$<5 \mathrm{~cm}$ & 74 & $66.0 \pm 14.2$ & $38.1-93.9$ & & 1 & & \\
\hline VI & & & & $<0.001$ & & & 0.001 \\
\hline Present & 116 & $20.0 \pm 4.9$ & $10.5-29.5$ & & 2.038 & $1.315-3.160$ & \\
\hline Absent & 92 & $47.0 \pm 11.0$ & $25.5-68.5$ & & 1 & & \\
\hline E-S grade & & & & 0.037 & & & 0.533 \\
\hline I-II & 158 & $43.0 \pm 6.3$ & $30.7-55.3$ & & 1 & & \\
\hline III-IV & 73 & $25.0 \pm 5.9$ & $13.4-36.6$ & & 1.144 & $0.749-1.749$ & \\
\hline TNM stage & & & & $<0.001$ & & & 0.005 \\
\hline I-II & 132 & $57.0 \pm 16.4$ & $24.8-89.2$ & & 1 & & \\
\hline III-IV & 91 & $17.0 \pm 4.7$ & $7.8-26.2$ & & 1.836 & $1.202-2.806$ & \\
\hline AFP level & & & & 0.078 & & & 0.107 \\
\hline$>20 \mathrm{ng} / \mathrm{ml}$ & 136 & $29.0 \pm 3.5$ & $22.1-35.9$ & & 1.396 & $0.930-2.094$ & \\
\hline$\leq 20 \mathrm{ng} / \mathrm{ml}$ & 80 & $47.0 \pm 11.2$ & $25.0-69.0$ & & 1 & & \\
\hline GRK3 expre & ssion & & & 0.002 & & & 0.012 \\
\hline High & 179 & $42.0 \pm 6.3$ & $29.7-54.3$ & & 0.545 & $0.340-0.873$ & \\
\hline Low & 52 & $16.0 \pm 6.1$ & $4.1-27.9$ & & 1 & & \\
\hline
\end{tabular}

*Partial data were not available, and statistical analyses were performed using available data. $\mathrm{HCC}$, hepatocellular carcinoma; $\mathrm{SE}$, standard error; $\mathrm{CI}$, confidence interval; HR, hazard ratio; HBsAg, hepatitis B surface antigen; VI, Vascular invasion; E-S, Edmondson-Steiner; TNM, tumor-node-metastasis; AFP, a-fetoprotein; GRK3, G-protein-coupled receptor kinase 3.

Furthermore, GRK3 expression was also found to be prognostic in all patients and 7 out of 10 subgroups of $\mathrm{HCC}$, i.e. tumor size $\geq 5 \mathrm{~cm}$, with vascular invasion, Edmondson-Steiner grade I-II, Edmondson-Steiner grade III-IV, TNM stage III-IV A, AFP level $\leq 20 \mathrm{ng} / \mathrm{ml}$ and AFP level $>20 \mathrm{ng} / \mathrm{ml}$, in univariate analysis (All $P<0.05$; Fig. 4). Multivariate Cox regression test revealed that GRK3 expression was of independent impacts on prognosis in all patients and 5 subgroups (tumor size $\geq 5 \mathrm{~cm}$, with vascular invasion, Edmondson-Steiner grade III-IV, TNM stage III-IV $\mathrm{A}_{\mathrm{A}}$ and AFP level $>20 \mathrm{ng} / \mathrm{ml}$ ) of HCC (All $P<0.05$; Table 4), together with some clinicopathologic variables.

\section{Discussion}

GRK3, an isoform of GRKs that has direct catalytic effects for phosphorylation and desensitization of GPCRs $[10,11]$, was proven to play pivotal roles in tissues, such as the nerve system [12-14]. Thus far, reports about GRK3 in human malignancies remains to be limited, but inconsistent, even opposite [15-18]. It was shown that GRK3 was negatively associated with aggressive behaviors in glioblastoma and breast cancer $[15,16]$, whereas this gene was also established to be involved in survival and proliferation of metastatic cells, as well as tumor growth, neuroendocrine differentiation and metastasis, in prostate cancer $[17,18]$. Therefore, GRK3 might be a protein that functions tissue-type specifically. Besides, expression and clinicopathologic significances of GRK3 in cancer have not been explored. The present study was designed to address the issues. In the first, authors found by Western blotting that GRK3 expression was low in tumor tissues, in contrast to adjacent non-tumor liver tissues, in half (4 out of 8) pairs of samples (Fig. 1), preliminarily indicating its frequent down-regulated expression in HCC. The subsequent finding based on HCC patients in a relatively recent time period as the training set is that H-score of GRK3 staining was much lower in tumor tissues than in non-tumor tissues (Fig. 2A-C). In addition, $\mathrm{H}$-scores of GRK3 staining were negatively correlated with tumor size, VI, TNM stage and serum AFP level (Table 1), variables that were linked to progression of HCC [24-27], under cut-off values derived from ROC curves (Fig. S2). Besides, these observations were strongly supported by similar ones in the validation set. In particular, the negative relationship between GRK3 expression and TNM stage as well as serum AFP level was found in both sets. No doubt TNM 

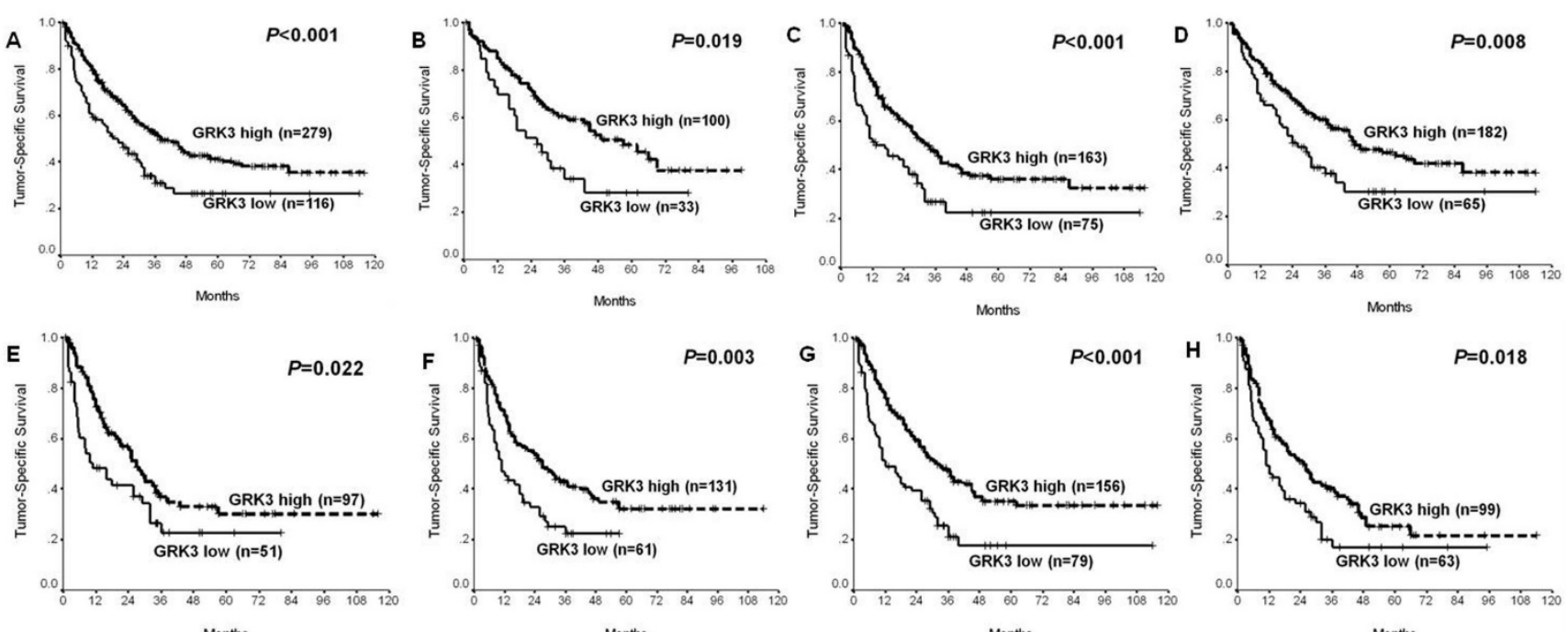

Figure 4. Significant prognostic impacts of G protein-coupled receptor kinase 3 (GRK3) in all patients and seven subgroups of hepatocellular carcinoma (HCC). (A) All patients; (B) alpha-fetoprotein (AFP) level $\leq 20 \mathrm{ng} / \mathrm{ml}$; (C) AFP level >20ng/ml; (D) Edmondson-Steiner (E-S) grade I-Il; (E) E-S grade III-IV; (F) With vascular invasion; (G) Tumor size $\geq 5$ $\mathrm{cm}$; $(\mathbf{H})$ tumor-node-metastasis $(\mathrm{TNM})$ stage III-IV $\mathrm{A}$.

stage largely reflects tumor progression, while AFP were long demonstrated to contribute to malignant phenotypes, for example, growth, host immune inhibition and metastasis, through multiple mechanisms in hepatocarcinogenesis [28-30]. Therefore, GRK3 seems to be a negative marker of HCC progression. Moreover, whether AFP is involved in GRK3-induced alterations in phenotypes and corresponding molecules of HCC might also be of interest. In the future, relative mechanistic investigations on GRK3 are quite expected.

On the other hand, the prognostic value of GRK3 in cancer remains unknown. In this work, the authors first showed in the training set that patients with high GRK3 expression had significantly good survival in univariate analysis (Fig. 3A, Table 2), while GRK3 remained to be significantly prognostic in multivariate Cox regression analysis (Table 2), adjusted for conventional clinicopathologic variables. Similar with results for clinicopathologic significance, its prognostic implication was also confirmed in the validation set (Fig. 3B, Table 3). Moreover, GRK3 expression was also revealed to distinguish good and poor survival in all patients and 7 out of 10 subsets of HCC in univariate analysis (Fig. 4), and independently predicted prognosis in all patients and 5 subsets based on multivariate Cox regression test (Table 4). All these data suggest that GRK3 might have a broad potential to serve as a promising biomarker for favorable prognosis in many groups of HCC. In view of the negative correlation between GRK3 expression and aggressive parameters, especially late TNM stage and high AFP level, the survival benefit of GRK3-high HCC might be easily understood. Thus, we here add a novel candidate of molecular markers in outcome prediction of HCC [7-9].

Collectively, our data establish that GRK3 is down-regulated and is predictive for favorable prognosis in HCC. Therefore, this gene might function as a tumor suppressor gene (TSG) in HCC.

Table 4. Significant prognostic values of GRK3 expression and other variables in all patients and univariate log-rank test-identified subgroups of HCC (estimated by multivariate Cox regression test)

\begin{tabular}{lllll}
\hline \multirow{2}{*}{ Sets } & \multicolumn{2}{l}{ GRK3 expression } & \multicolumn{2}{l}{$\begin{array}{l}\text { Other independent } \\
\text { prognostic factors }\end{array}$} \\
\cline { 2 - 5 } & HR & $95 \% \mathrm{CI}$ & $P^{*}$ & E-S grade, VI, TNM stage \\
All patients & 0.610 & $0.436-0.853$ & $\mathbf{0 . 0 0 4}$ & E-S grade, VI, TNM stage, \\
Tumor size $\geq 5 \mathrm{~cm}$ & 0.547 & $0.370-0.809$ & $\mathbf{0 . 0 0 3}$ & $\begin{array}{l}\text { AFP level } \\
\text { With VI }\end{array}$ \\
& 0.612 & $0.400-0.937$ & $\mathbf{0 . 0 2 4}$ & TNM stage \\
E-S grade I-II & 0.663 & $0.419-1.050$ & 0.080 & VI, TNM stage \\
E-S grade III-IV & 0.538 & $0.316-0.915$ & $\mathbf{0 . 0 2 2}$ & None \\
TNM stage III-IV A & 0.541 & $0.344-0.850$ & $\mathbf{0 . 0 0 8}$ & AFP level \\
AFP level & 0.632 & $0.346-1.157$ & 0.137 & E-S grade \\
$\leq 20 n g / m l$ & & & & \\
AFP level & 0.552 & $0.365-0.835$ & $\mathbf{0 . 0 0 5}$ & VI, TNM stage \\
>20ng/ml & & & &
\end{tabular}

*Partial data were not available, and statistical analyses were performed using available data. GRK3, G-protein-coupled receptor kinase 3; HCC, hepatocellular carcinoma; HR, hazard ratio; CI, confidence interval; E-S, Edmondson-Steiner; VI,

Vascular invasion; TNM, tumor-node-metastasis; AFP, a-fetoprotein.

\section{Supplementary Material}

Supplementary figures.

http://www.jcancer.org/v08p1972s1.pdf

\section{Competing Interests}

The authors declare no competing interests.

\section{References}

1. El-Serag HB. Hepatocellular carcinoma. N Engl J Med. 2011; 365: 1118-27.

2. Bertuzzo VR, Cescon M, Ravaioli M, Grazi GL, Ercolani G, Del Gaudio M, et al. Analysis of factors affecting recurrence of hepatocellular carcinoma after 
liver transplantation with a special focus on inflammation markers. Transplantation. 2011; 91: 1279-85.

3. Silva MF, Sapisochin G, Strasser SI, Hewa-Geeganage S, Chen J, Wigg AJ, et al. Liver resection and transplantation offer similar 5-year survival for Child-Pugh-Turcotte A HCC-patients with a single nodule up to $5 \mathrm{~cm}$ : a multicenter, exploratory analysis. Eur J Surg Oncol. 2013; 39: 386-95.

4. Tandon P, Garcia-Tsao G. Prognostic indicators in hepatocellular carcinoma: a systematic review of 72 studies. Liver Int. 2009; 29: 502-10.

5. Jin J, Zhu P, Liao Y, Li J, Liao W, He S. Elevated preoperative aspartate aminotransferase to lymphocyte ratio index as an independent prognostic factor for patients with hepatocellular carcinoma after hepatic resection. Oncotarget. 2015; 6: 19217-27.

6. Goh BK, Teo JY, Chan CY, Lee SY, Jeyaraj P, Cheow PC, et al. Importance of tumor size as a prognostic factor after partial liver resection for solitary hepatocellular carcinoma: Implications on the current AJCC staging system. J Surg Oncol 2016; 113: 89-93.

7. Tan N, Liu Q, Liu X, Gong Z, Zeng Y, Pan G, et al. Low expression of B-cell-associated protein 31 in human primary hepatocellular carcinoma correlates with poor prognosis. Histopathology. 2016; 68: 221-9.

8. Fang F, Chang RM, Yu L, Lei X, Xiao S, Yang H, et al. MicroRNA-188-5p suppresses tumor cell proliferation and metastasis by directly targeting FGF5 in hepatocellular carcinoma. J Hepatol. 2015; 63: 874-85.

9. Yan TH, Yang H, Jiang JH, Lu SW, Peng CX, Que HX, et al. Prognostic significance of long non-coding RNA PCAT-1 expression in human hepatocellular carcinoma. Int J Clin Exp Pathol. 2015; 8: 4126-31.

10. Benovic JL, Kuhn H, Weyand I, Codina J, Caron MG, Lefkowitz RJ. Functional desensitization of the isolated beta-adrenergic receptor by the beta-adrenergic receptor kinase: potential role of an analog of the retinal protein arrestin (48-kDa protein). Proc Natl Acad Sci U S A. 1987; 84: 8879-82.

11. Pitcher JA, Freedman NJ, Lefkowitz RJ. G protein-coupled receptor kinases. Annu Rev Biochem. 1998; 67: 653-92.

12. Kato A, Reisert J, Ihara S, Yoshikawa K, Touhara K. Evaluation of the role of $g$ protein-coupled receptor kinase 3 in desensitization of mouse odorant receptors in a Mammalian cell line and in olfactory sensory neurons. Chem Senses. 2014; 39: 771-80.

13. Lowe JD, Sanderson HS, Cooke AE, Ostovar M, Tsisanova E, Withey SL, et al. Role of $G$ protein-coupled receptor kinases 2 and 3 in $\mu$-opioid receptor desensitization and internalization. Mol Pharmacol. 2015; 88: 347-56.

14. Ahmed MR, Bychkov E, Li L, Gurevich VV, Gurevich EV. GRK3 suppresses L-DOPA-induced dyskinesia in the rat model of Parkinson's disease via its RGS homology domain. Sci Rep. 2015; 5: 10920.

15. Woerner BM, Luo J, Brown KR, Jackson E, Dahiya SM, Mischel P, et al. Suppression of G-protein-coupled receptor kinase 3 expression is a feature of classical GBM that is required for maximal growth. Mol Cancer Res. 2012; 10: $156-66$.

16. Billard MJ, Fitzhugh DJ, Parker JS, Brozowski JM, McGinnis MW, Timoshchenko RG, et al. G protein coupled receptor kinase 3 regulates breast cancer migration, invasion, and metastasis. PLoS One. 2016; 11: e0152856.

17. Li W, Ai N, Wang S, Bhattacharya N, Vrbanac V, Collins M, et al. GRK3 is essential for metastatic cells and promotes prostate tumor progression. Proc Natl Acad Sci U S A. 2014; 111: 1521-6.

18. Sang M, Hulsurkar M, Zhang X, Song $H$, Zheng D, Zhang $Y$, et al. GRK3 is a direct target of CREB activation and regulates neuroendocrine differentiation of prostate cancer cells. Oncotarget. 2016; 7: 45171-85.

19. Edmondson HA, Steiner PE. Primary carcinoma of the liver: a study of 100 cases among 48,900 necropsies. Cancer. 1954; 7: 462-503.

20. McClelland RA, Finlay P, Walker KJ, Nicholson D, Robertson JF, Blamey RW, et al. Automated quantitation of immunocytochemically localized estrogen receptors in human breast cancer. Cancer Res. 1990; 50: 3545-50.

21. Righi L, Papotti MG, Ceppi P, Billè A, Bacillo E, Molinaro L, et al. Thymidylate synthase but not excision repair cross-complementation group 1 tumor expression predicts outcome in patients with malignant pleural mesothelioma treated with pemetrexed-based chemotherapy. J Clin Oncol. 2010; 28: 1534-9.

22. Ortolan E, Arisio R, Morone S, Bovino P, Lo-Buono N, Nacci G, et al. Functional role and prognostic significance of CD157 in ovarian carcinoma. J Natl Cancer Inst. 2010; 102: 1160-77.

23. Stanaway FF, Gnjidic D, Blyth FM, Le Couteur DG, Naganathan V, Waite L, et al. How fast does the Grim Reaper walk? Receiver operating characteristics curve analysis in healthy men aged 70 and over. BMJ. 2011; 343: d7679.

24. Kim SU, Jung KS, Lee S, Park JY, Kim do Y, Ahn SH, et al. Histological subclassification of cirrhosis can predict recurrence after curative resection of hepatocellular carcinoma. Liver Int. 2014; 34: 1008-17.

25. Li J, Liu Y, Yan Z, Wan X, Xia Y, Wang K, et al. A nomogram predicting pulmonary metastasis of hepatocellular carcinoma following partial hepatectomy. Br J Cancer. 2014; 110: 1110-7.

26. Varona MA, Soriano A, Aguirre-Jaime A, Garrido S, Oton E, Diaz D, et al. Risk factors of hepatocellular carcinoma recurrence after liver transplantation: accuracy of the alpha-fetoprotein model in a single-center experience. Transplant Proc. 2015; 47: 84-9.

27. Takeishi K, Maeda T, Tsujita E, Yamashita Y, Harada N, Itoh S, et al. Predictors of intrahepatic multiple recurrences after curative hepatectomy for hepatocellular carcinoma. Anticancer Res. 2015; 35: 3061-6.

28. Zheng L, Gong W, Liang P, Huang X, You N, Han KQ et al. Effects of AFP-activated PI3K/Akt signaling pathway on cell proliferation of liver cancer. Tumour Biol. 2014; 35: 4095-9.
29. Pardee $\mathrm{AD}$, Shi J, Butterfield LH. Tumor-derived a-fetoprotein impairs the differentiation and $\mathrm{T}$ cell stimulatory activity of human dendritic cells. J Immunol. 2014; 193: 5723-32.

30. Lu Y, Zhu M, Li W, Lin B, Dong X, Chen Y, et al. Alpha fetoprotein plays a critical role in promoting metastasis of hepatocellular carcinoma cells. J Cell Mol Med. 2016; 20: 549-58. 